\title{
miR-211 suppresses hepatocellular carcinoma by downregulating SATB2
}

\author{
Guixing Jiang ${ }^{1}$, Yunfu Cui ${ }^{2}$, Xin $\mathrm{Yu}^{3}$, Zhengrong Wu${ }^{1}$, Guoping Ding ${ }^{1}$, Liping Cao ${ }^{1}$ \\ ${ }^{1}$ Department of Hepatopancreatobiliary Surgery, Sir Run Run Shaw Hospital, School of Medicine, Zhejiang University, \\ Hangzhou, China \\ ${ }^{2}$ Department of Hepatopancreatobiliary Surgery, Second Affiliated Hospital of Harbin Medical University, Harbin, China \\ ${ }^{3}$ Department of Biochemistry and Molecular Biology, Institute of Basic Medical Sciences, Chinese Academy of Medical \\ Sciences, Beijing, China
}

Correspondence to:

Liping Cao, e-mail: caolipingzju@126.com

Keywords: hepatocellular carcinoma, microRNAs, miR-211, SATB2

Received: January 08, $2015 \quad$ Accepted: January 31, 2015

Published: March 25, 2015

\section{ABSTRACT}

Dysregulation of microRNAs (miRs) is involved in carcinogenesis. Deregulation of miR-211 has recently been observed in many tumors, but its function in hepatocellular carcinoma (HCC) is still unknown. Here we found that miR-211 was decreased in HCC cancer tissues compared with adjacent normal tissues. We also found that overexpression of miR-211 repressed proliferation and invasion in HepG2 and SMMC7721 cells. Luciferase reporter assays and western blot indicated that special AT-rich sequence-binding protein-2 (SATB2), is a direct target of miR-211. The expression of SATB2 was upregulated in HCC cancer tissues and cell lines and miR-211 levels inversely correlated with SATB2 levels in HCC. Importantly, SATB2 rescued the miR-211-mediated inhibition of cell invasion and proliferation. Finally, reintroduction of miR-211 repressed tumor formation of HCC in xenograft mice. This study provides insights into molecular mechanisms that miR-211 contributed to HCC.

\section{INTRODUCTION}

Hepatocellular carcinoma (HCC) is the sixth most prevalent cancer and the third most frequent cause of cancer mortality worldwide, leading to more than 600,000 deaths each year [1, 2]. HCC is especially common in China, with the mortality rate the second highest [3]. In China, more than 110000 people die from liver cancer each year, causing $45 \%$ of the liver cancer death in the world [3]. Despite therapeutic advances, the 5-year survival rate of HCC is still below 5\% [4-6]. HCC is the result of a multistep process, which involves the accumulation of several structural and genomic alterations $[7,8]$. Hence, it is urgent to develop novel strategies for the early diagnosis, prediction of the prognosis and therapeutic target of patients with HCC.

MiRNAs are a group of endogenous, small, noncoding RNAs that negatively regulate gene expression via binding to the 3'untranslated region ( $3^{\prime} \mathrm{UTR}$ ) of mRNA, leading to repress post-transcripional translation or the degradation of the target mRNA [9-12]. Increasing researches have indicated that deregulation of miRNAs plays large roles in the initiation and progression of many cancers such as breast cancer, gastric cancer, lung cancer, and bladder cancer [13-17]. Through regulating various target mRNAs gene, miRNAs are involved in many biological processes including cell proliferation, apoptosis, invasion, migration, differentiation, angiogenesis and immune response, metabolism, and so on [18-21]. Therefore, better knowledge of changes in miRNA gene expression during live carcinogenesis and metastasis may provide new avenues for HCC diagnostic and treatment regiments [22-26].

In this study, we aimed to determine the expression and function of miR-211 in HCC and investigate the molecular mechanism of miR-211 in the initiation and progression of HCC.

\section{RESULT}

MiR-211 is downregulated in HCC cell lines and tissues

The decrease of miR-211 was found in 33 of $40 \mathrm{HCC}$ tissues compared with the corresponding non-tumor tissues (Figure 1A). As shown in Figure 1B, the expression of 
A

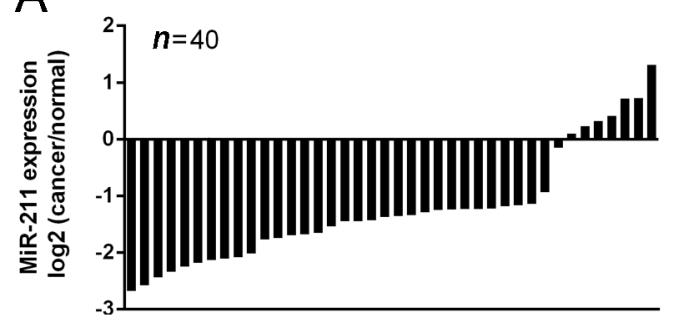

C

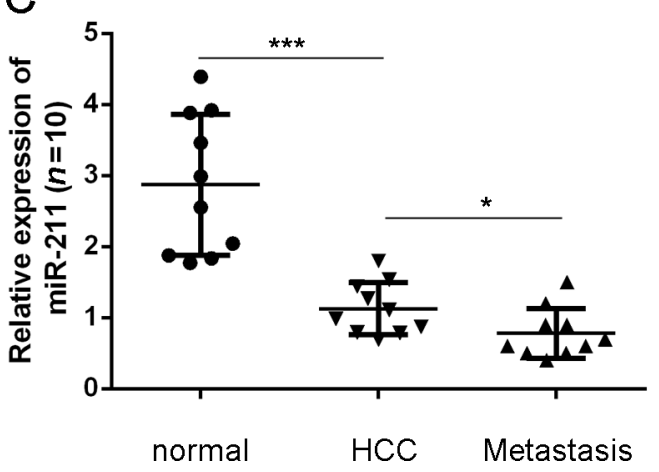

B

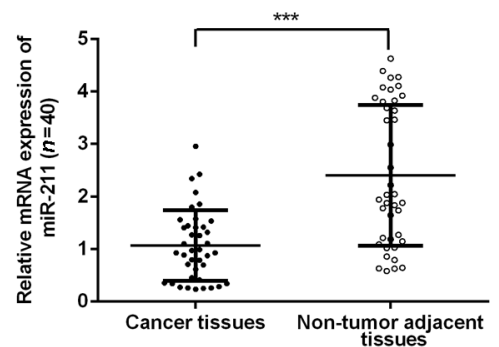

D

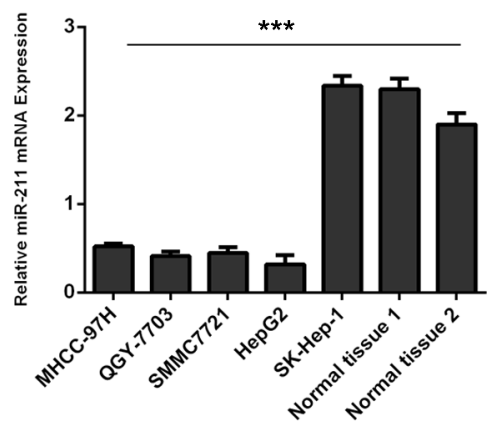

Figure 1: miR-211 is downregulated in HCC cell lines and tissues. (A) qRT-PCR analysis of miR-211 expression in 40 pairs HCC tissues and their corresponding no tumor tissues. The expression of miR-211 was normalized to U6 snRNA. (B) The expression of miR-211 in HCC tissues was significant lower than in adjacent tissues. (C) The expression of miR-211 in 10 pairs lymph node metastases, HCC tissues and their corresponding to no tumor tissues. (D) Expression levels of miR-211 in four cell lines (MHCC-97H, QGY-7703, SMMC7721 and HepG2) compared with one liver adenocarcinoma cell line, SK-Hep-1, and two adjacent nonneoplastic tissues were detected using qRT-PCR analysis. ${ }^{*} p<0.05$ and $* * * p<0.001$.

miR-211 in HCC tissues was lower than in adjacent tissues (Figure 1B, $p<0.001$ ). Moreover, tissues from lymph node metastases also expressed lower levels of miR-211 compared with primary HCC tissues and the adjacent normal tissue (Figure 1C). As shown in Figure 1D, the expression of miR-211 was significantly down-regulated in four cell lines (MHCC-97H, QGY-7703, SMMC7721 and HepG2) compared with one liver adenocarcinoma cell line, SK-Hep-1, and two adjacent non-neoplastic tissues.

\section{Upregulation of miR-211 inhibits cell proliferation}

To study the role of miR-211 in HCC development, SMMC7721 and HepG2 were transfected with miR-211 mimics or inhibitor with high transfection efficiency (Figure 2A and 2B). Down expression of miR-211 inhibited the growth rate of HCC cells compared with control cells in both SMMC7721 and HepG2 cells (Figure 2C and 2D). Conversely, miR-211 mimics promoted the proliferation of the HepG2 cells in both SMMC7721 and HepG2 cells (Figure 2C and 2D).

\section{Upregulation of mir-211 inhibits cell invasion}

Overexpression of miR-211 can promote the invasion of HepG2 cells and SMMC7721 compared with the control whereas miR-211 inhibitor inhibited cell invasion (Figure 3A and 3B). The relative invasive cells of each group were shown in the right.

\section{STAB2 is a direct target of mir-211}

Using bioinformatics analysis, we found that 3'-UTR of STAB2 contained a conserved putative target site for miR-211 (Figure 4A). Therefore, the 3'-UTR of human STAB2 was amplified and inserted into downstream of the luciferase gene in the pGL3-control vector. As shown in Figure 4B, miR-211 mimics repressed the luciferase activity. Mutation of miR-211 binding site from the STAB2 3'-UTR largely abolished the effects of miR-211 mimics. Meanwhile, miR-211 repressed the mRNA expression of STAB2. In addition, Western blot analysis also showed that ectopic expression of miR-211 markedly suppressed STAB2 expression in HepG2 cell line (Figure 4C and 4D).

\section{miR-211 regulated cell proliferation and invasion through inhibiting SATB2}

The SATB2 expression vector pcDNA-SATB2 was used to restore SATB2 expression (Figure 5A and 5B). Overexpression of SATB2 promoted the HepG2 cells proliferation and invasion (Figure 5C and 5D). As expected, the ectopic expression of SATB2rescued the 

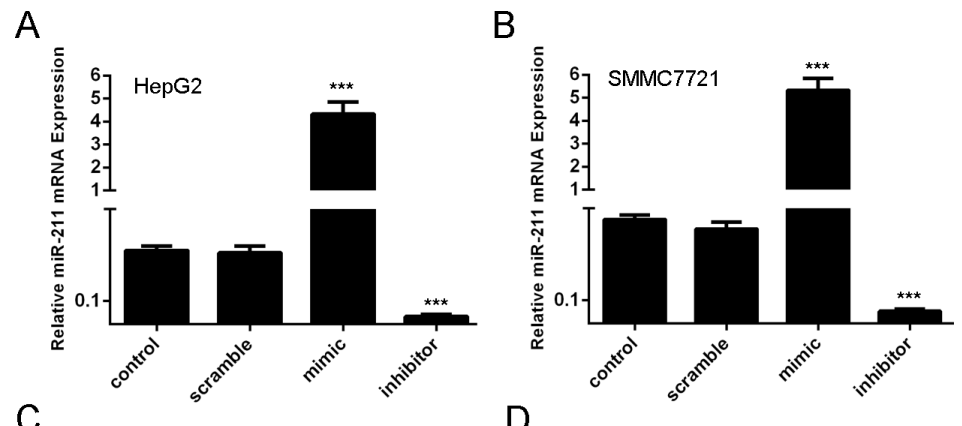

C

D
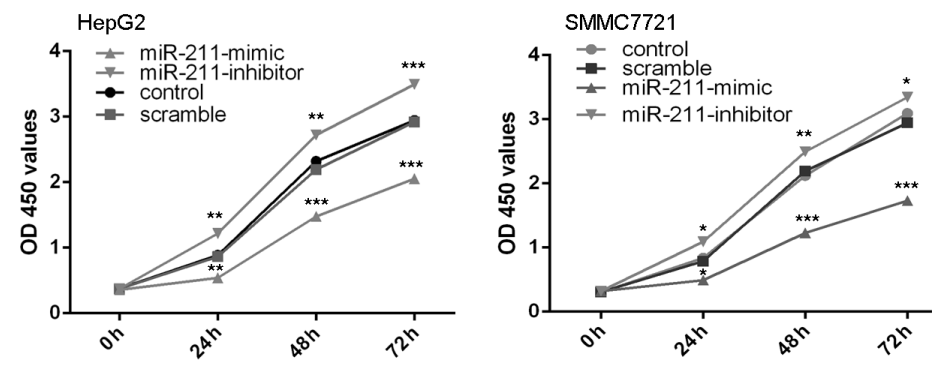

Figure 2: Upregulation of miR-211 inhibits cell proliferation. (A) miR-211 mimics can enhance the expression of miR-211 and miR-211 inhibitor can repress the expression of miR-211 in the HepG2 cells. (B) miR-211 mimics can enhance the expression of miR211 and miR-211 inhibitor can repress the expression of miR-211 in the SMMC7721 cells. (C) CCK-8 proliferation assay showed that overexpression of miR-211 significantly inhibited the growth rate of cells compared with control cells in both and HepG2cells. Conversely, miR-211 inhibitor significantly promoted the proliferation of the HepG2 cells. (D) CCK-8 proliferation assay showed that overexpression of miR-211 significantly inhibited the growth rate of cells compared with control cells in both and SMMC7721 cells. Conversely, miR-211 inhibitor significantly promoted the proliferation of the SMMC7721 cells. ${ }^{*} p<0.05$, ${ }^{*} p<0.01$, and $* * * p<0.001$.

\section{A}
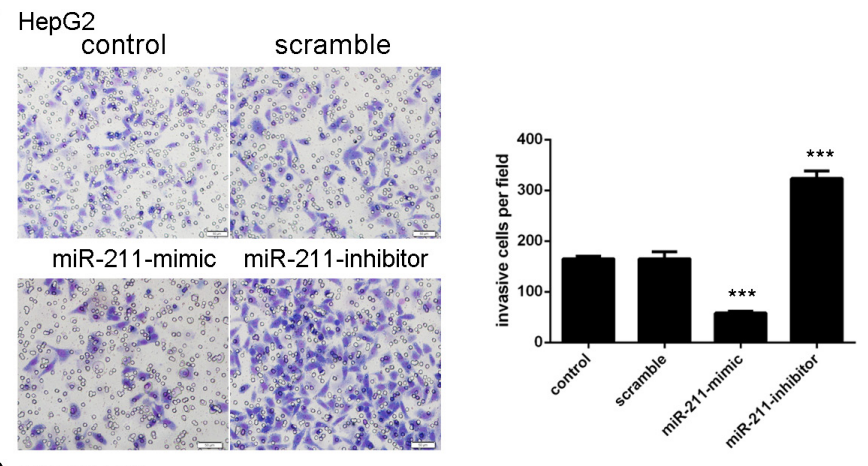

B SMMC7721

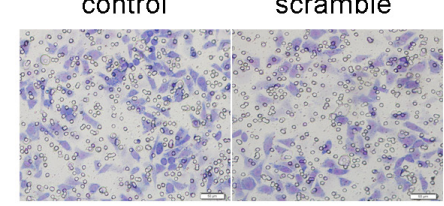

miR-211-mimic miR-211-inhibitor
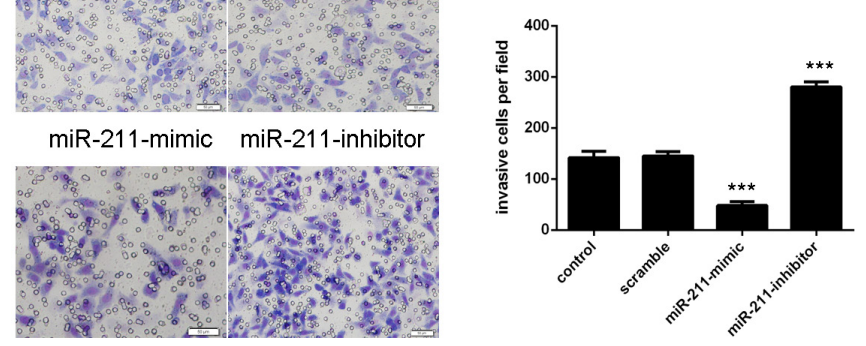

Figure 3: Upregulation of miR-211 inhibits cell invasion. (A) Upexpression of miR-211 can significantly promoted the HepG2 cells invasion whereas miR-211 inhibitor inhibitedHepG2cell invasion. The relative invasive cells of each group have been shown in the right. (B) Upexpression of miR-211 can significantly promoted the SMMC7721 cells invasion whereas miR-211 inhibitor inhibited SMMC7721 cell invasion. The relative invasive cells of each group have been shown in the right. $* * * p<0.001$. 


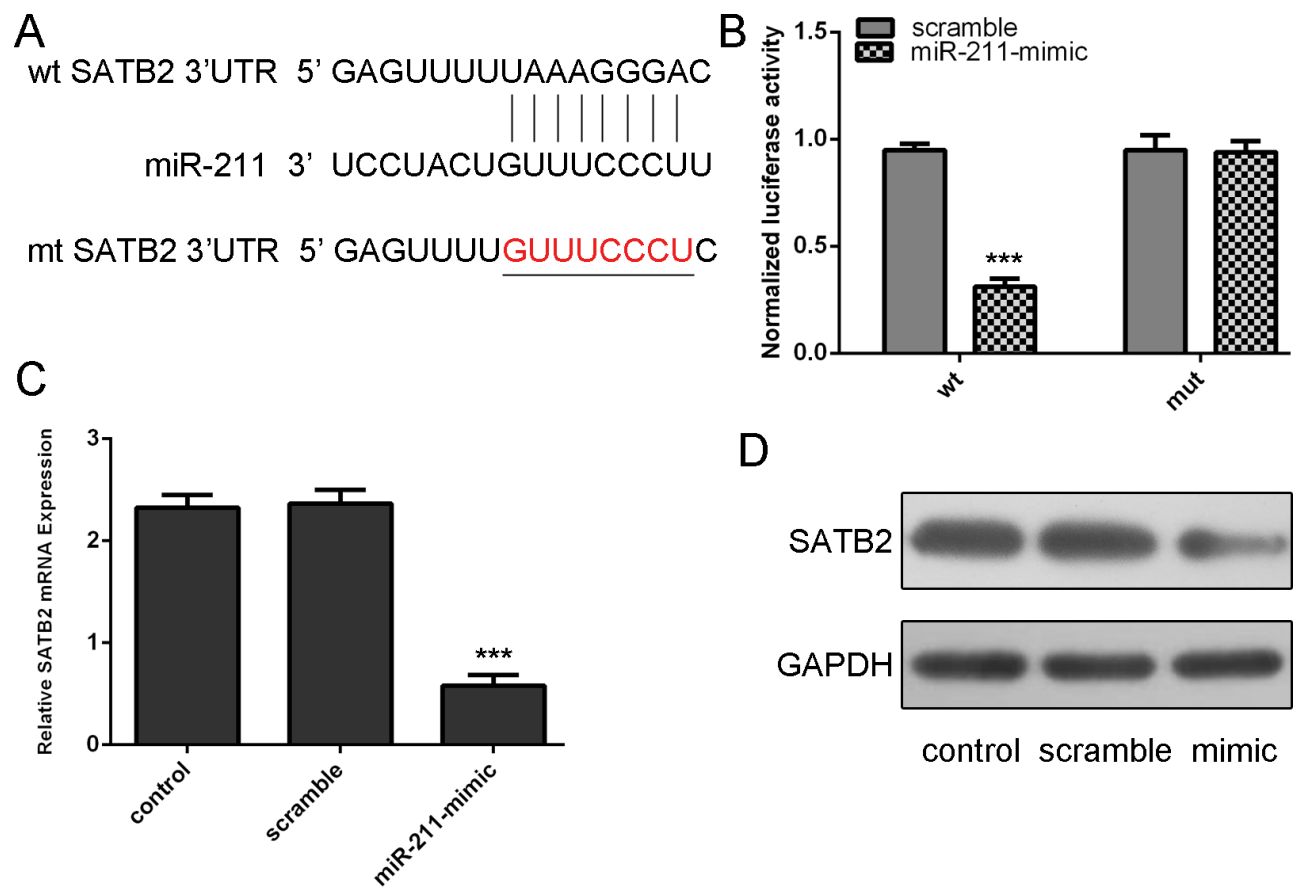

Figure 4: STAB2 is a direct target of miR-211. (A) Predicted miR-211 target sequence in the 3'UTR of STAB2 and mutant containing 8 altered nucleotides in the 3'UTR of STAB2. (B) The analysis of the relative luciferase activities of STAB2-WT, STAB2-MUT in the HepG2 cells. (C) qRT-PCR analysis of STAB2 mRNA expression in the HepG2cellscells after treatment with miRNA mimics or scramble or no transfection. The expression of STAB2 was normalized to GAPDH. (D) Western blot analysis of STAB2 expression in the HepG2 cells transfected with miR-564 mimics or scramble or no transfection. GAPDH was also detected as a loading control. $* * * p<0.001$.
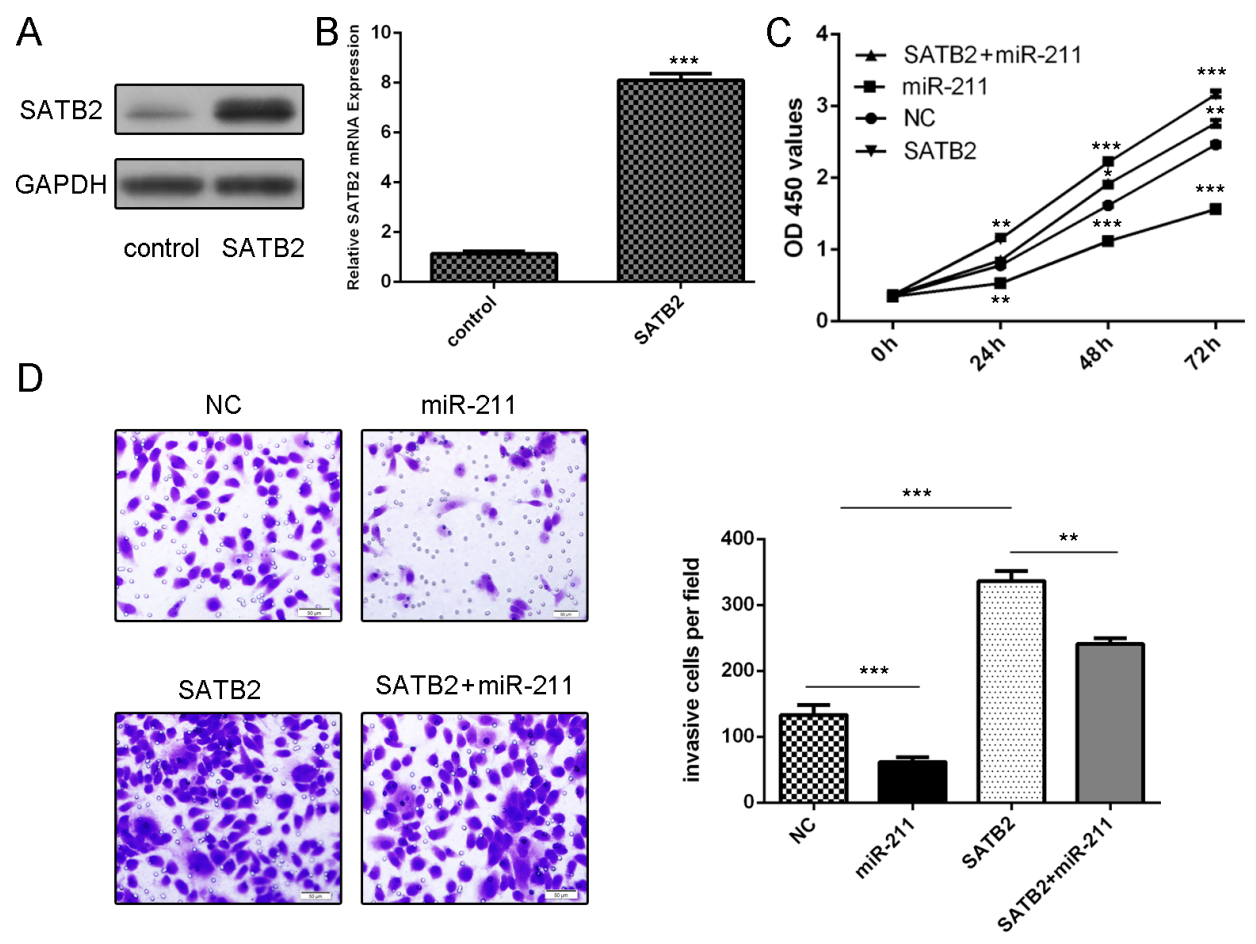

Figure 5: miR-211 regulated cell proliferation and invasion through inhibiting SATB2. (A) The protein expression of SATB2 was detected using western blot in HepG2 cells. GAPDH was also detected as a loading control. (B) The mRNA expression of SATB2 was detected using qRT-PCR in HepG2 cells. The expression of STAB2 was normalized to GAPDH. (C) Cell proliferation was determined by CCK-8 assay. The ectopic expression of SATB2 rescued the miR-211-mediated inhibition of cell proliferation in HepG2 cells. (D) The ectopic expression of SATB2 rescued themiR-211-mediated inhibition of cell invasion in HepG2 cells. ${ }^{*} p<0.05$, and ${ }^{* *} p<0.01, * * * p<0.001$. 
miR-211-mediated inhibition of cell proliferation and migration in HepG2 cells (Figure 5C and 5D).

\section{STAB2 was inversely expressed with miR-211 in HCC patients}

As shown in Figure 6A and 6B, STAB2 was upregulated in four cell lines (MHCC-97H, QGY-7703, SMMC7721 and HepG2) compared with one liver adenocarcinoma cell line, SK-Hep-1, and two adjacent tissues. To further validate our findings, the levels of STAB2 were measured in 20 human primary HCC and pair-matched peri-tumoral tissues. As shown in Figure 6C, the expression of STAB2in HCC tissues was lower than in adjacent tissues (Figure 1C, $p<0.001$ ). The increase of STAB2 was found in 19 of 20 HCC tissues compared with the corresponding non-tumor tissues (Figure 6D). Comparison of miR-211 levels and levels corresponding to STAB2 in HCC exhibited inverse correlation between STAB2 and miR-211 $\left(r^{2}=0.426, P=0.0018\right)$ (Figure 6E).

\section{miR-211 inhibited the growth of HepG2-engrafted tumors}

MiR-211 mimic injection repressed the growth of HepG2-engrafted tumors compared to scrambled oligonucleotides-treated tumors (Figure 7A). In agreement with the tumor growth curve, the volumes and weights of tumors treated by miR-211 mimics were also lower than scrambled mimics-treated tumors (Figure 7B and 7C). Western blot analysis in randomly selected xenograft mouse tumors showed that miR-211 mimics-injecting tumors expressed lower levels of STAB2 than scramble controls (Figure 7E). Moreover, Ki-67 was lower in the miR-211 mimics-injecting tumors compared to the scrambled mimics-treated tumors (Figure 7D).

\section{DISCUSSION}

The important role of deregulated miRNAs in cancer has been proved by many researches $[18,19,28-30]$. Our study showed that miR-211 expression was downregulated in HCC cells and HCC tissues. Furthermore, ectopic expression of miR-211 repressed the proliferation and invasion of HCC cells. As for the mechanism, our results indicated that miR-211 directly targeted SATB2 to inhibit cell proliferation and invasion in HCC cells. Importantly, SATB2 rescued the miR-211-mediated inhibition of cell invasion and proliferation. Moreover, our investigation for the expression of SATB2 and miR-211 in 20HCC patients indicated that there was an inverse correlation between miR-211 and SATB2 levels. These findings suggest that miR-211 may play an important role in promoting carcinogenesis of HCC.
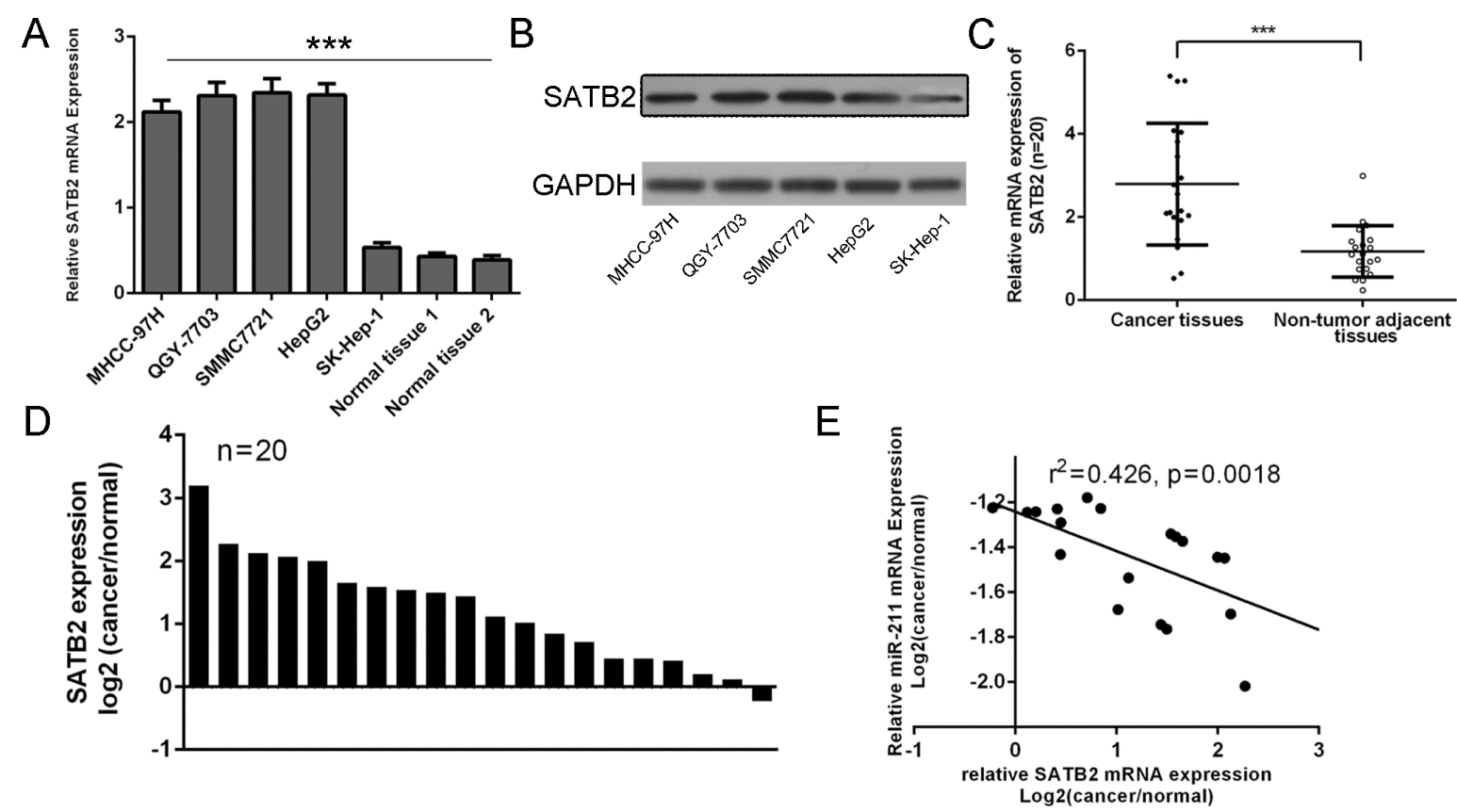

Figure 6: STAB2 was inversely expressed with miR-211 in HCC patients. (A) Expression levels of STAB2 in four cell lines (MHCC-97H, QGY-7703, SMMC7721 and HepG2) compared with one liver adenocarcinoma cell line, SK-Hep-1, and two adjacent nonneoplastic tissues were detected using qRT-PCR analysis. (B) The protein expression levels of STAB2 in four cell lines (MHCC97H, QGY-7703, SMMC7721 and HepG2) compared with one liver adenocarcinoma cell line were detected using western blot. (C) The expression of STAB2in HCC tissues was significant lower than in adjacent tissues. (D) The increase of STAB2 was found in 19 of 20 compared with the corresponding non-tumor tissues. (E) Comparison of miR-211 levels and levels corresponding to STAB2 in HCC exhibited significantly inverse correlation between STAB2 and miR-211 $(r 2=0.426, p=0.0018)$. ${ }^{* * *} p<0.001$. 
A

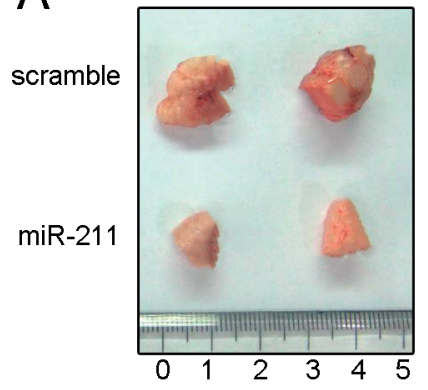

D
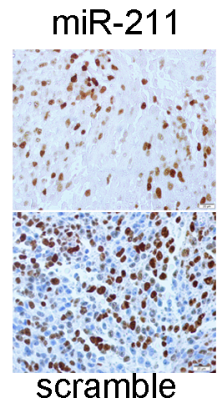

B

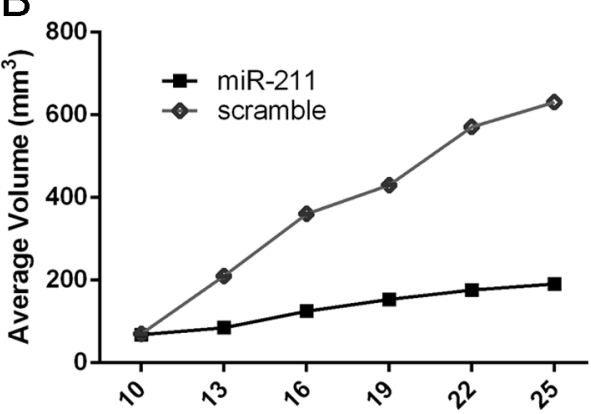

$E$
C

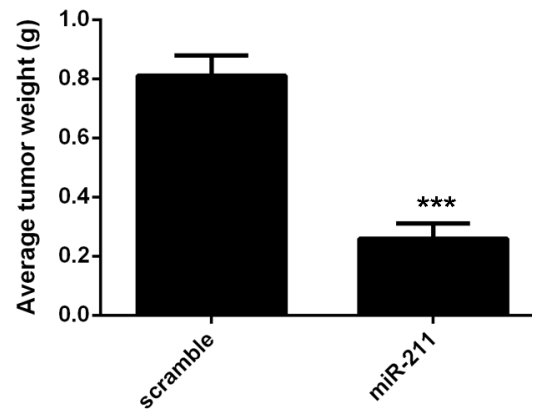

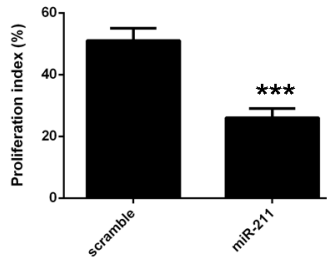

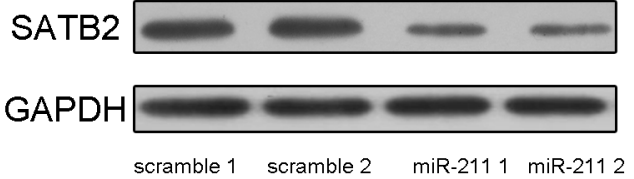

Figure 7: miR-211 repressed the growth of HepG2-engrafted tumors. (A) Representative tumors were photographed at 15 days after the first treatment with miR-211 mimic or scramble. (B) Tumor weight averages between scrambled and miR-211 mimics-treated mice groups at the end of the experiment (day 25). (C) Graph representing tumor volumes at the indicated days during the experiment for the two groups: scrambled mimics, miR-211 mimics. (D) Injection of miR-211 reduced Ki-67 protein expression in HepG2 xenograft tumors. (E) Injection of miR-211 reduced STAB2 protein levels in HepG2 xenograft tumors. Represented are 2 tumors from each group. $* * * p<0.001$.

Researchers have illustrated that miR-211 is abnormally expressed in various tumors and directly involves in human cancer processes, such as cell proliferation, migration and metastasis [31-36]. MiR211 was upregulated in oral carcinoma and higher miR211 expression was associated with nodal metastasis, vascular invasion, and poor prognosis of oral carcinoma [32]. Moreover, enforced miR-211 expression increased the proliferation, migration, and anchorage-independent colony formation of oral carcinoma cells. Furthermore, enforced expression of miR-211 promoted tumor cell growth at least in part by down-regulating the CHD5 tumor suppressor [31]. On the other hand, another study showed that miR-211 was a suppressor of melanoma invasion during human melanoma progression $[34,37$, 38]. To our knowledge, the role and mechanism of miR211 in HCC have not been completely understood. Our results indicated that miR-211 was down-regulated in HCC tissues compared with adjacent non-neoplastic tissues. Moreover, tissues from lymph node metastases expressed lower levels of miR-211 compared with primary HCC tissues and the adjacent normal tissue, indicating an inverse relationship between miR-211 and the metastatic status of HCC. Furthermore, over-expression of miR211 could repress HCC cell proliferation and invasion. These results suggested that miR-211 might act as a tumor suppressor whose down-regulation contributed to the progression and metastasis of HCC.
Integrating bioinformatics and experimental assays, we identified SATB2 as a direct downstream target of miR-211 in HCC cells. Complementary sequence of miR-211 was identified in the 3'UTR of SATB2 mRNA. Overexpression of miR-211 reduced SATB2 both mRNA and protein levels in HCC cells. Moreover, miR-211 decreased the luciferase reporter activity of wild-type 3'UTR but not mutant 3'UTR of SATB2. Human special AT-rich sequence-binding protein-2 (SATB2) is a novel AT-rich DNA binding protein, which is involved in regulating gene expression through altering chromatin structure [39-42]. Previous studies have shown that SATB2 directly interacts with the activity of transcription factors which regulate cortical neurons differentiation and craniofacial development [43, 44]. It has been demonstrated that the expression of SATB2 was lower in primary colorectal cancer (CRC) [45]. Furthermore, down-regulated expression of SATB2 was associated with metastasis and poor prognosis in CRC [45]. Another study has reported that SATB2 was associated with increasing tumor grade and poorer overall survival in breast cancer [46]. However, the expression and mechanism of SATB2 in HCC remain unknown. In our study, SATB2 expression is up-regulated in HCC tissues compared with adjacent pair-matched non-tumor tissues. The expression of SATB2 is also increased in the HCC cells. Moreover, SATB2 rescued the miR-211mediated inhibition of cell invasion and proliferation and 
there was an inverse correlation between miR-211 and SATB2 levels in HCC tissues. These results demonstrate thatSATB2 is a functional target gene of miR-211 in HCC.

To our knowledge, there is no study on miR-211 and HCC tumorigenicity in a xenograft model. In our research, the tumor-suppressive role of miR-211 in vivo was treated through direct miRNA mimics injection. Our result proved that miR-211 significantly inhibited the growth of HCC cells. Further western blot analysis demonstrated the negative regulation of miR-211 to SATB2. These results suggest that miR-211 might be a potential therapeutic choice in HCC.

In conclusion, we identified that miR-211 acted a tumor suppressive miRNA in HCC tumorigenesis and progression. Given that reintroduction of miR-211 inhibited tumor formation in xenograft model, this mature miRNA could serve as a potential therapeutic strategy for HCC. Our findings are encouraging and suggest that this miRNA could be targeted for the development of novel treatment for $\mathrm{HCC}$ in the future.

\section{MATERIALS AND METHODS}

\section{Patients and samples}

Tumor tissues from HCC patients and paired adjacent non-cancerous specimens were obtained from patients undergoing surgery at Sir Run Run Shaw Hospital. None of these patients had received local or systemic anticancer treatment before surgery. The patient information is summarized in Supplementary Table S1. All tissues were collected immediately during surgery and stored at $-80^{\circ} \mathrm{C}$ until the RNA and protein were later extracted. The studies were approved by the ethics committee of Sir Run Run Shaw Hospital.

\section{Cell lines and culture}

Cell lines derived from human hepatocellular carcinoma (MHCC-97H, QGY-7703, SMMC7721, HepG2) and liver adenocarcinoma (SK-Hep-1) were incubated and cultured in Dulbecco's modified Eagle's medium (DMEM, Hyclone, Logan, UT, USA), which was also supplemented with 10\% fetal bovine serum (FBS, Hyclone, Thermo Fisher Scientific, Mordialloc, Victoria, Australia).

\section{RNA extraction and quantitative real-time PCR}

Total RNA was extracted from cell lines or frozen tissues using Qiazol reagent and miRNeasy mini kit (Qiagen, Valencia, CA, and USA). The qRT-PCR reactions were performed using iQSYBR Green super mix (Bio-Rad, Hercules, CA). To determine the threshold cycle $(\mathrm{Ct})$ when exponential amplification of the PCR products began, an iQ-5 (Bio-Rad) was used to monitor the PCR in real-time. The average $\mathrm{Ct}$, from triplicate assays, was used for further calculations. Primers are listed in Supplementary Table S2. Relative expression levels were normalized to control. The endogenous U6 snRNA or GAPDH was chosen as the internal control.

\section{Oligonucleotides and transfection}

MiR-211 mimics/inhibitors and negative control molecules (scramble control mimic and inhibitor) and pcDNA-SATB2 were purchased from Dharmacon (Austin, TX). Cell transfection was performed using DharmFECT1 (Dharmacon) until a final concentration of $20 \mathrm{nM}$. Medium was changed after $6 \mathrm{~h}$. After transfected and cultured for $48 \mathrm{~h}$, cells were collected for Western blot and qRT-PCR analyses.

\section{Cell proliferation assay}

Cell Counting Kit (CCK-8) assay was used for cell proliferation analysis. Cells were cultured in $10 \% \mathrm{CCK}$ 8 (DOJINDO) diluted in normal culture media at $37^{\circ} \mathrm{C}$. When visual color conversion appeared, quantification was carried out on a micro titer plate reader (Spectra Rainbow; Tecan).

\section{Cell invasion assay}

Invasion assays were performed in triplicate using Transwell invasion chambers coated with Matrigel (50 $\mu \mathrm{l}$ per filter) (BD Biosciences, Franklin Lakes, NJ, USA) in accordance to the manufacturer's protocol. After being cultured for $48 \mathrm{~h}$, cells were transferred on the top of Matrigel-coated invasion chambers in a $1 \%$ fetal calf serum DMEM/F12 $\left(2 \times 10^{4}\right.$ cells/well $)$. The lower chambers were added with DMEM/F12 containing $10 \%$ fetal calf serum. Cells were incubated for $24 \mathrm{~h}$ at $37^{\circ} \mathrm{C}$ in an atmosphere containing 5\% CO2. Subsequently, invaded cells on the lower surface were stained with crystal violet stain and counted under a light microscope.

\section{Western blot}

Western blots were performed as previously described [27]. Proteins were resolved with10\% SDSPAGE gel, subsequently transferred to the nitrocellulose membrane. Then the membranes were, blocked in 5\% nonfat dry milk in Tris-buffered saline ( $\mathrm{pH}$ 7.4) containing $0.05 \%$ Tween-20 and blotted with a rabbit polyclonal antibody against SATB2 and GAPDH (1:1,000; Santa Cruz Biotechnology, Inc., Santa Cruz, CA, USA) and goat anti-rabbit IgG. GAPDH were chosen as a loading control. Protein bands were detected by chemilumine scenceusing the ECL system (Vigorous Biotech, Beijing, China). 


\section{Luciferase reporter assays}

Cells in 24-well plates (50\% confluency) were cotransfected with miR-211 mimic $(20 \mathrm{nM})$ and STAB2 3'UTR Reporter (200 ng). Luciferase activity was detected $24 \mathrm{~h}$ later using the Dual-Glo luciferase assay system (Promega, Fitchburg, WI, USA) according to the manufacture's protocol.

\section{In vivo studies}

Animal xenograft model studies were carried out according to institutional guidelines; HepG2 cells $\left(3 \times 10^{6}\right)$ were injected subcutaneously into the posterior flanks of 6-week female nude mice, with a frequency of every 3 days for a total of six times. On the 10 th day after injection, tumor diameters were measured every 3 days. On the 25 th days after injection, mice were killed. Tumors were collected and weighted after necropsy. Tumor volume was calculated as length $\times$ width $2 \times 1 / 2 \mathrm{~mm}^{3}$. When tumor size reached $50 \mathrm{~mm}^{3}$, miRNA mimics diluted in Lipofectamine 2000 (Invitrogen) solution ( $100 \mathrm{nmol}$ mimics in $100 \mu \mathrm{l}$ total volume) were injected into the tumors.

\section{Statistics}

Data were presented as the mean \pm standard deviation (SD) from three separate experiments. When two groups were compared, the differences between groups were analyzed using Student's $t$-test and when more than two groups were compared, a one-way analysis of variance (ANOVA) was used. The differences between groups of metastasis in vivo were analyzed using the $\chi 2$ test. All statistical analyses were performed with SPSS 16.0 (SPSS Inc., USA). The difference was considered statistically significant at $P<0.05$.

\section{ACKNOWLEDGMENTS}

This work was supported by grants from the National Natural Science Foundation of China (NSFC) (Grant Numbers: 81200319 and 81272671).

\section{CONFLICT OF INTEREST}

The authors declare no conflict of interest.

\section{REFERENCES}

1. Chen Y, Hu W, Lu Y, Jiang S, Li C, Chen J, Tao D, Liu Y, Yang Y, Ma Y. A TALEN-based specific transcript knockdown of PIWIL2 suppresses cell growth in HepG2 tumor cell. Cell Prolif. 2014; 47:448-456.

2. Huang S, Xie Y, Yang P, Chen P, Zhang L. HCV core protein-induced down-regulation of microRNA-152 promoted aberrant proliferation by regulating Wnt1 in HepG2 cells. PloS One. 2014; 9:e81730.

3. Huang J. Current progress in epigenetic research for hepatocarcinomagenesis. Sci China C Life Sci. 2009; 52:31-42.

4. Jung CJ, Iyengar S, Blahnik KR, Ajuha TP, Jiang JX, Farnham PJ, Zern M. Epigenetic modulation of miR-122 facilitates human embryonic stem cell self-renewal and hepatocellular carcinoma proliferation. PloS One. 2011; 6:e27740.

5. Furuta M, Kozaki K, Tanimoto K, Tanaka S, Arii S, Shimamura T, Niida A, Miyano S, Inazawa J. The tumorsuppressive miR-497-195 cluster targets multiple cell-cycle regulators in hepatocellular carcinoma. PloS One. 2013; 8:e60155.

6. Ladeiro Y, Couchy G, Balabaud C, Bioulac-Sage P, Pelletier L, Rebouissou S, Zucman-Rossi J. MicroRNA profiling in hepatocellular tumors is associated with clinical features and oncogene/tumor suppressor gene mutations. Hepatology. 2008; 47:1955-1963.

7. Furuta M, Kozaki KI, Tanaka S, Arii S, Imoto I, Inazawa J. miR-124 and miR-203 are epigenetically silenced tumorsuppressive microRNAs in hepatocellular carcinoma. Carcinogenesis. 2010; 31:766-776.

8. Lang Q, Ling C. MiR-124 suppresses cell proliferation in hepatocellular carcinoma by targeting PIK3CA. Biochem Biophys Res Commun. 2012; 426:247-252.

9. Li M, Yu M, Liu C, Zhu H, He X, Peng S, Hua J. miR-34c works downstream of p53 leading to dairy goat male germline stem-cell (mGSCs) apoptosis. Cell Prolif. 2013; 46:223-231.

10. Ohdaira H, Sekiguchi M, Miyata K, Yoshida K. MicroRNA-494 suppresses cell proliferation and induces senescence in A549 lung cancer cells. Cell Prolif. 2012; 45:32-38.

11. Li J, You T, Jing J. MiR-125b inhibits cell biological progression of Ewing's sarcoma by suppressing the PI3K/Akt signalling pathway. Cell Prolif. 2014; 47:152-160.

12. Lee HK, Finniss S, Cazacu S, Bucris E, Ziv-Av A, Xiang C, Bobbitt K, Rempel SA, Hasselbach L, Mikkelsen T, Slavin S, Brodie C. Mesenchymal stem cells deliver synthetic microRNA mimics to glioma cells and glioma stem cells and inhibit their cell migration and self-renewal. Oncotarget. 2013; 4:346-361.

13. Yang WB, Chen PH, Hsu Ts, Fu TF, Su WC, Liaw H, Chang WC, Hung JJ. Sp1-mediated microRNA-182 expression regulates lung cancer progression. Oncotarget. 2014; 5:740-753.

14. Wang Z, Wang N, Liu P, Chen Q, Situ H, Xie T, Zhang J, Peng C, Lin Y, Chen J. MicroRNA-25 regulates chemoresistance-associated autophagy in breast cancer cells, a process modulated by the natural autophagy inducer isoliquiritigenin. Oncotarget. 2014; 5:7013-7026.

15. Itesako T, Seki N, Yoshino H, Chiyomaru T, Yamasaki T, Hidaka H, Yonezawa T, Nohata N, Kinoshita T, Nakagawa M, Enokida $\mathrm{H}$. The microRNA expression signature of bladder 
cancer by deep sequencing: the functional significance of the miR-195/497 cluster. PloS One. 2014; 9:e84311.

16. Xu Y, Jin J, Liu Y, Huang Z, Deng Y, You T, Zhou T, Si J, Zhuo W. Snail-regulated MiR-375 inhibits migration and invasion of gastric cancer cells by targeting JAK2. PloS One. 2014; 9:e99516.

17. Zhao G, Cai C, Yang T, Qiu X, Liao B, Li W, Ji Z, Zhao J, Zhao H, Guo M, Ma Q, Xiao C, Fan Q, Ma B. MicroRNA-221 induces cell survival and cisplatin resistance through PI3K/Akt pathway in human osteosarcoma. PloS One. 2013; 8:e53906.

18. Bier A, Giladi N, Kronfeld N, Lee HK, Cazacu S, Finniss S, Xiang C, Poisson L, deCarvalho AC, Slavin S, Jacoby E, Yalon M, Toren A, Mikkelsen T, Brodie C. MicroRNA-137 is downregulated in glioblastoma and inhibits the stemness of glioma stem cells by targeting RTVP-1. Oncotarget. 2013; 4:665-676.

19. Zhang C, Liu J, Wang X, Wu R, Lin M, Laddha SV, Yang Q, Chan CS, Feng Z. MicroRNA-339-5p inhibits colorectal tumorigenesis through regulation of the MDM2/ p53 signaling. Oncotarget. 2014; 5:9106-9117.

20. Li H, Yang BB. Stress response of glioblastoma cells mediated by miR-17-5p targeting PTEN and the passenger strand miR-17-3p targeting MDM2. Oncotarget. 2012; 3:1653-1668.

21. Fei $\mathrm{B}, \mathrm{Wu} \mathrm{H}$. MiR-378 inhibits progression of human gastric cancer MGC-803 cells by targeting MAPK1 in vitro. Oncol Res. 2013; 20:557-564.

22. Giovannini C, Minguzzi $M$, Baglioni $M$, Fornari $F$, Giannone F, Ravaioli M, Cescon M, Chieco P, Bolondi L, Gramantieri L. Suppression of p53 by Notch3 is mediated by Cyclin G1 and sustained by MDM2 and miR221 axis in hepatocellular carcinoma. Oncotarget. 2014; 5:10607-10620.

23. Zhang K, Chen J, Chen D, Huang J, Feng B, Han S, Chen Y, Song H, De W, Zhu Z, Wang R, Chen L. Aurora-A promotes chemoresistance in hepatocelluar carcinoma by targeting NF-kappaB/microRNA-21/PTEN signaling pathway. Oncotarget. 2014; 5:12916-12935.

24. Zhou HC, Fang JH, Luo X, Zhang L, Yang J, Zhang C, Zhuang SM. Downregulation of microRNA-100 enhances the ICMT-Rac1 signaling and promotes metastasis of hepatocellular carcinoma cells. Oncotarget. 2014; 5:12177-12188.

25. Liu LL, Lu SX, Li M, Li LZ, Fu J, Hu W, Yang YZ, Luo RZ, Zhang CZ, Yun JP. FoxD3-regulated microRNA-137 suppresses tumour growth and metastasis in human hepatocellular carcinoma by targeting AKT2. Oncotarget. 2014; 5:5113-5124.

26. Heo MJ, Kim YM, Koo JH, Yang YM, An J, Lee SK, Lee SJ, Kim KM, Park JW, Kim SG. microRNA-148a dysregulation discriminates poor prognosis of hepatocellular carcinoma in association with USP4 overexpression. Oncotarget. 2014; 5:2792-2806.
27. Li Z, Yu X, Liang J, Wu WK, Yu J, Shen J. Leptin downregulates aggrecan through the p38-ADAMST pathway in human nucleus pulposus cells. PloS One. 2014; 9:e109595.

28. Xiong X, Ren HZ, Li MH, Mei JH, Wen JF, Zheng CL. Down-regulated miRNA-214 induces a cell cycle G1 arrest in gastric cancer cells by up-regulating the PTEN protein. Pathol Oncol Res. 2011; 17:931-937.

29. Zhou J, Song S, Cen J, Zhu D, Li D, Zhang Z. MicroRNA-375 is downregulated in pancreatic cancer and inhibits cell proliferation in vitro. Oncol Res. 2012; 20:197-203.

30. Schirmer U, Doberstein K, Rupp AK, Bretz NP, Wuttig D, Kiefel H, Breunig C, Fiegl H, Muller-Holzner E, Zeillinger R, Schuster E, Zeimet AG, Sultmann H, Altevogt P. Role of miR-34a as a suppressor of L1CAM in endometrial carcinoma. Oncotarget. 2014; 5:462-472.

31. Cai C, Ashktorab H, Pang X, Zhao Y, Sha W, Liu Y, Gu X. MicroRNA-211 expression promotes colorectal cancer cell growth in vitro and in vivo by targeting tumor suppressor CHD5. PloS One. 2012; 7:e29750.

32. Chang KW, Liu CJ, Chu TH, Cheng HW, Hung PS, $\mathrm{Hu}$ WY, Lin SC. Association between high miR-211 microRNA expression and the poor prognosis of oral carcinoma. J Dent Res. 2008; 87:1063-1068.

33. Dai X, Rao C, Li H, Chen Y, Fan L, Geng H, Li S, Qu J, Hou L. Regulation of pigmentation by microRNAs: MITFdependent microRNA-211 targets TGF-beta receptor 2. Pigment Cell Melanoma Res. 2014. [Epub ahead of print]

34. Sakurai E, Maesawa C, Shibazaki M, Yasuhira S, Oikawa H, Sato M, Tsunoda K, Ishikawa Y, Watanabe A, Takahashi K, Akasaka T, Masuda T. Downregulation of microRNA-211 is involved in expression of preferentially expressed antigen of melanoma in melanoma cells. Int $\mathrm{J}$ Oncol. 2011; 39:665-672.

35. Maftouh M, Avan A, Funel N, Frampton AE, Fiuji H, Pelliccioni S, Castellano L, Galla V, Peters GJ, Giovannetti E. miR-211 modulates gemcitabine activity through downregulation of ribonucleotide reductase and inhibits the invasive behavior of pancreatic cancer cells. Nucleosides Nucleotides Nucleic Acids. 2014; 33:384-393.

36. Li XY, Zhang K, Jiang ZY, Cai LH. MiR-204/miR-211 downregulation contributes to candidemia-induced kidney injuries via derepression of Hmx1 expression. Life Sci. 2014; 102:139-144.

37. Levy C, Khaled M, Iliopoulos D, Janas MM, Schubert S, Pinner S, Chen PH, Li S, Fletcher AL, Yokoyama S, Scott KL, Garraway LA, Song JS, Granter SR, Turley SJ, Fisher DE, et al. Intronic miR-211 assumes the tumor suppressive function of its host gene in melanoma. Mol Cell. 2010; 40:841-849.

38. Margue C, Philippidou D, Reinsbach SE, Schmitt M, Behrmann I, Kreis S. New target genes of MITF-induced microRNA-211 contribute to melanoma cell invasion. PloS One. 2013; 8:e73473. 
39. Zhao X, Qu Z, Tickner J, Xu J, Dai K, Zhang X. The role of SATB2 in skeletogenesis and human disease. Cytokine Growth Factor Rev. 2014; 25:35-44.

40. Yang MH, Yu J, Chen N, Wang XY, Liu XY, Wang S, Ding YQ. Elevated microRNA-31 expression regulates colorectal cancer progression by repressing its target gene SATB2. PloS One. 2013; 8:e85353.

41. Conner JR, Hornick JL. SATB2 is a novel marker of osteoblastic differentiation in bone and soft tissue tumours. Histopathology. 2013; 63:36-49.

42. Wei J, Shi Y, Zheng L, Zhou B, Inose H, Wang J, Guo XE, Grosschedl R, Karsenty G. miR-34s inhibit osteoblast proliferation and differentiation in the mouse by targeting SATB2. J Cell Biol. 2012; 197:509-521.
43. Huang Y, Song NN, Lan W, Hu L, Su CJ, Ding YQ, Zhang L. Expression of transcription factor Satb2 in adult mouse brain. Anat Rec. 2013; 296:452-461.

44. Zhang L, Song NN, Chen JY, Huang Y, Li H, Ding YQ. Satb2 is required for dendritic arborization and soma spacing in mouse cerebral cortex. Cereb Cortex. 2012; 22:1510-1519.

45. Wang S, Zhou J, Wang XY, Hao JM, Chen JZ, Zhang XM, Jin H, Liu L, Zhang YF, Liu J, Ding YQ, Li JM. Downregulated expression of SATB2 is associated with metastasis and poor prognosis in colorectal cancer. J Pathol. 2009; 219:114-122.

46. Patani N, Jiang W, Mansel R, Newbold R, Mokbel K. The mRNA expression of SATB1 and SATB2 in human breast cancer. Cancer Cell Int. 2009; 9:18. 